Revisión sistemática

\title{
Revisión sistemática sobre el cáncer de vejiga y exposición ocupacional
}

\author{
Systematic Review of Bladder Cancer and Occupational Exposure
}

\author{
Jezabel López Brito', Azahara Álvarez Llergo², Lara $M^{a}{ }^{a}$ Calvo Pérez³ ${ }^{3}$ Rosa $M^{a}$ Moreno Jiménez ${ }^{1}$ \\ 1. Unidad Docente de Medicina del Trabajo de Canarias. España \\ 2. Unidad Docente de Medicina del Trabajo de Madrid. España \\ 3. Unidad Docente de Medicina del Trabajo de Navarra. España \\ Recibido: 23-05-2020 \\ Aceptado: 28-06-2020

\section{Correspondencia} \\ Jezabel lópez Brito \\ Dirección: calle Cerrillo 38. Arucas. CP: 35400. Las Palmas \\ Tfno: 646128321 \\ correo electrónico: jlopbri@gmail.com
}

Este trabajo se ha desarrollado dentro del Programa Científico de la Escuela Nacional de Medicina del Trabajo del Instituto de Salud Carlos III en convenio con la Unidad Docente de Medicina del Trabajo de la Comunidad de Madrid, Unidad Docente de Navarra y la Unidad Docente de Canarias.

Resumen

Introducción: El cáncer de vejiga representa la neoplasia del tracto urinario más frecuente a nivel mundial. Los principales factores de riesgo asociados al cáncer de vejiga son el tabaco y la exposición ocupacional. En este sentido, fue una de las primeras enfermedades en las que se identificaron agentes químicos industriales como potenciales desencadenantes.

Objetivos: Revisar la literatura científica disponible acerca de la relación entre la exposición laboral a distintas sustancias y el desarrollo de cáncer de vejiga, así como las principales profesiones asociadas al mismo.

Métodos: Revisión sistemática de la literatura científica mediante búsqueda en las bases de datos Medline (PubMed), SCOPUS, EMBASE, WOS, Cochrane, IBECS, LILACS y Google académico, hasta el 20 de Noviembre de 2019.

Resultados: Se recuperaron 73 registros, de los que finalmente se incluyeron un total de 17 estudios tras aplicar los criterios de inclusión y exclusión. Se evidenció que las principales sustancias relacionadas de forma significativa con el desarrollo de cáncer de vejiga fueron las aminas aromáticas, hidrocarburos aromáticos policíclicos y disolventes (tricloroetileno, percloroetileno). Así mismo, los sectores en los que encontramos este tipo de agentes incluyen la industria textil, agricultura, metalurgia, peluquería, pintores y trabajadores de imprenta, entre otros.

Conclusiones: Se dispone de suficiente evidencia científica que apoya una relación directa entre la exposición laboral a distintos agentes, principalmente aminas aromáticas, hidrocarburos policíclicos y disolventes como el tricloroetileno y el desarrollo de cáncer de vejiga.

Med Segur Trab (Internet). 2019;66(259):81-99

Palabras clave: cáncer de vejiga, exposición ocupacional.

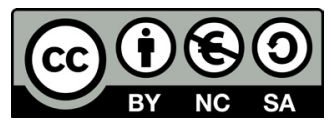

https://creativecommons.org/licenses/by-nc-sa/4.0/ 


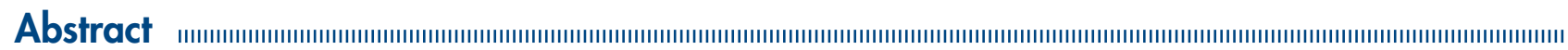

Background: Urinary bladder neoplasm represents the most common urinary tract cancer worldwide.

Tobacco and occupational exposure are the main risk factors associated to bladder cancer. Likewise, it was one of the first illnesses in which chemical agents were identified as potential triggers.

Objectives: To review the available scientific literature about the relationship between occupational exposure to certain substances and bladder cancer development, as well as the main associated professions.

Methods: Systematic review of scientific articles through bibliographic search in Medline (PubMed), SCOPUS, EMBASE, WOS, Cochrane, IBECS, LILACS and Google Scholar, published until November, the 20th 2019.

Results: 73 references were retrieved, 17 articles remained after applying the inclusion and exclusion criteria. According to the evidence, the main carcinogenic substances related to bladder cancer were aromatic amines, polycyclic aromatic hydrocarbons, solvents (trichloroethylene, perchlorethylene). These agents can be found mainly in the following sectors and industries: textile, farming, metallurgy, hairdressing, painters and printing.

Conclusions: There is scientific evidence to support a direct relationship between occupational exposure to different kind of agents: aromatic amines, polycyclic aromatic hydrocarbons and solvents as trichloroethylene predominantly, and bladder cancer.

Med Segur Trab (Internet). 2019;66(259):81-99

Keywords: urinary bladder neoplasms, occupational exposure. 


\section{INTRODUCCIÓN}

El cáncer es una de las causas que lidera la mortalidad a nivel mundial(1). En la actualidad, se considera que el origen del cáncer tiene naturaleza multifactorial, interviniendo factores de tipo ambiental, ocupacional, sociales y genéticos. Más del $90 \%$ de las neoplasias malignas pueden ser atribuidas a factores ambientales y externos.

En lo que a neoplasias del tracto urinario se refiere, la de vejiga es la más frecuente a nivel mundial ${ }^{1}$. Supone el cuarto y décimo segundo cáncer más común en hombres y mujeres, respectivamente. En cuanto a mortalidad, es la octava causa de muerte por cáncer en hombres y la decimocuarta en mujeres ${ }^{3}$. En España se diagnostican unos 12.200 casos anuales, lo que representa el $11 \%$ de los tumores del sexo masculino (10.700 casos) y el 2,4\% de los femeninos (1.500 casos). La incidencia en nuestro país es de las más altas del mundo siendo el cuarto tumor más frecuente en hombres, tras los de pulmón, próstata y colorrectales ${ }^{4}$. Según la Sociedad Española de Oncología Médica, los cánceres más frecuentes diagnosticados en España en 2019 han sido los de colon y recto (44.937 nuevos casos), próstata (34.394), mama (32.536), pulmón (29.503) y vejiga urinaria (23.819)5.

Los principales factores de riesgo asociados al cáncer de vejiga son el tabaco y la exposición ocupacional. Se estima que el tabaco es el causante del 50\% de los mismos. El riesgo varía con el sexo, tiempo expuesto al tabaco y tipo de tabaco. La segunda fuente de agentes carcinógenos más frecuente es a través de la exposición profesional. En el cáncer de vejiga fue una de las primeras enfermedades donde se identificaron agentes químicos industriales como potenciales desencadenantes ${ }^{6}$, tales como hidrocarburos aromáticos policíclicos, nitrosaminas, arsénico y, particularmente, aminas aromáticas. Otros factores de riesgo descritos son la esquistosomiasis urinaria, ciertos agentes quimioterápicos como la ciclofosfamida, radioterapia pélvica y algunos factores dietéticos y de hábitos de vida ${ }^{7}$.

De la misma manera, en relación al cáncer de vejiga de origen ocupacional, en la mayoría de los países, a través de regulación normativa, se ha reducido notablemente su incidencia ${ }^{8}$. Ejemplos incluyen las Directivas europeas 90/394/CEE, 97/42/CE y 1999/38/ CE relativa a la protección de los trabajadores contra los riesgos relacionados con la exposición a agentes carcinógenos o mutágenos durante el trabajo?.

Se ha descrito mayor riesgo de cáncer de vejiga en distintos grupos laborales como pintores, trabajadores de la industria del caucho, metal, plástico, peluqueros, trabajadores de limpieza en seco, del transporte y de imprentas Estos grupos están expuestos a aminas aromáticas, hidrocarburos aromáticos policíclicos, humos de escape diesel e hidrocarburos clorados. Todos ellos implicados como posibles agentes carcinógenos de vejiga ${ }^{10,11,12}$.

Llevar a cabo políticas de prevención primaria, evitando o limitando la exposición a factores de riesgo, es importante para reducir la incidencia, morbilidad y mortalidad relacionadas con esta patología.

El objetivo de este trabajo es establecer qué agentes carcinógenos laborales predominan en la actualidad como principales desencadenantes del cáncer de vejiga, así como las principales profesiones asociadas al mismo.

\section{OBJETIVOS}

\section{General:}

- Revisar la literatura científica disponible acerca de la relación entre la exposición laboral a distintas sustancias y el desarrollo de cáncer de vejiga.

\section{Específicos:}

- Establecer las principales sustancias implicadas en la aparición de cáncer de vejiga. 
- Identificar los empleos/trabajos en los que se utilizan los agentes cancerígenos relacionados con el cáncer de vejiga.

\section{MATERIAL Y MÉTODOS}

Se ha realizado una revisión sistemática de la literatura acerca del cáncer de vejiga causado por exposición profesional.

La búsqueda de los documentos bibliográficos se llevó a cabo en las siguientes bases de datos: MEDLINE (a través de Pubmed), Scopus, WOS (Web of Science), EMBASE, IBECS (Índice Bibliográfico Español de Ciencias de la Salud), Cochrane Library Plus y LILACS (Literatura Latinoamericana y del Caribe en Ciencias de la Salud). Para definir los términos de la búsqueda se empleó el MeSH (thesaurus desarrollado por la U.S. National Library of Medicine), considerándose adecuados "urinary bladder neoplasms" y "occupational exposure", como descriptores. En el anexo III se encuentran las estrategias de búsqueda de las distintas bases de datos.

La búsqueda bibliográfica concluyó el 20 de noviembre de 2019. Se utilizaron los filtros (límites): "publicados en los últimos 5 años", "humanos" e idioma inglés y castellano. Esta misma estrategia se adaptó a las características de cada una de las bases de datos consultadas (ver anexo III).

En el presente estudio se siguieron las directrices de la Declaración PRISMA ${ }^{14}$ durante su elaboración para favorecer la apreciación crítica e interpretación del mismo.

\section{SELECCIÓN DE ESTUDIOS}

Se seleccionaron para su revisión aquellos artículos que cumplían los siguientes criterios de inclusión y se eliminaron a los que se aplicó los criterios de exclusión.

\section{Criterios de inclusión}

- Centrados en cáncer de vejiga

- Relacionados con enfermedades profesionales

- Tipos de estudios: metaanálisis, revisión sistemática, ensayo clínico, cohorte, caso control, series de casos $(\mathrm{N}>10)$

\section{Criterios de exclusión}

- Estudio publicado con anterioridad a 1 de enero de 2014 (últimos 5 años)-

- Tipos de estudios: a propósito de un caso, serie de casos $(\mathrm{N}<10)$, abstract a congresos, cartas al editor, revisiones narrativas

En primer lugar, los artículos fueron seleccionados a partir de sus títulos y resúmenes, de acuerdo con los criterios de inclusión y exclusión establecidos previamente. La selección se realizó de forma independiente por todas las autoras. A continuación se procedió a la lectura del texto completo de los documentos, llegando posteriormente a un consenso sobre la adecuación o no de su inclusión en la revisión sistemática.

Tras este primer cribado se procedió a la recuperación de los artículos a texto completo, a través de la biblioteca Nacional de Ciencias de la Salud del Instituto de Salud Carlos III. Se diseñó una tabla de síntesis de información para la lectura sistemática de los artículos, en la que se incluyeron los siguientes datos: autor y año, país, diseño del estudio, período de estudio, población de estudio y resultados. La extracción de datos se realizó por todos los miembros de manera independiente.

La evaluación de la calidad metodológica de los artículos seleccionados se realizó utilizando las pautas de la declaración STROBE (Strengthening the reporting of 
Observational studies in Epidemiology $)^{15}$ para los estudios observacionales y la declaración PRISMA (Preferred Reporting Items for Systematic reviews and MetaAnalyses) para la valoración crítica de meta-análisis y revisiones sistemáticas incluidas $^{14}$.

\section{RESULTADOS}

\section{Selección de artículos}

Tras aplicar las estrategias de búsqueda en las distintas bases de datos se obtuvieron un total de 70 referencias. Una vez leídos los resúmenes y títulos, se eliminaron 53 artículos por estar duplicados o no cumplir los criterios de inclusión.

Tras realizar el primer cribado, se disponía de un total de 19 artículos, de los que 2 fueron eliminados por estar incluídos en otros metaanálisis ${ }^{30,31}$ (ver Figura 1).

Finalmente la revisión sistemática contó con 17 artículos ${ }^{1,8,13,16-29}$, clasificados según el diseño del estudio en 6 revisiones sistemáticas y metanálisis ${ }^{8,13,17-20}, 5$ estudios de cohortes ${ }^{16,22,23,25-26}, 4$ estudios de casos y controles ${ }^{1,21,24,28}$ y 2 estudios de serie de $\operatorname{casos}^{29,30}$.

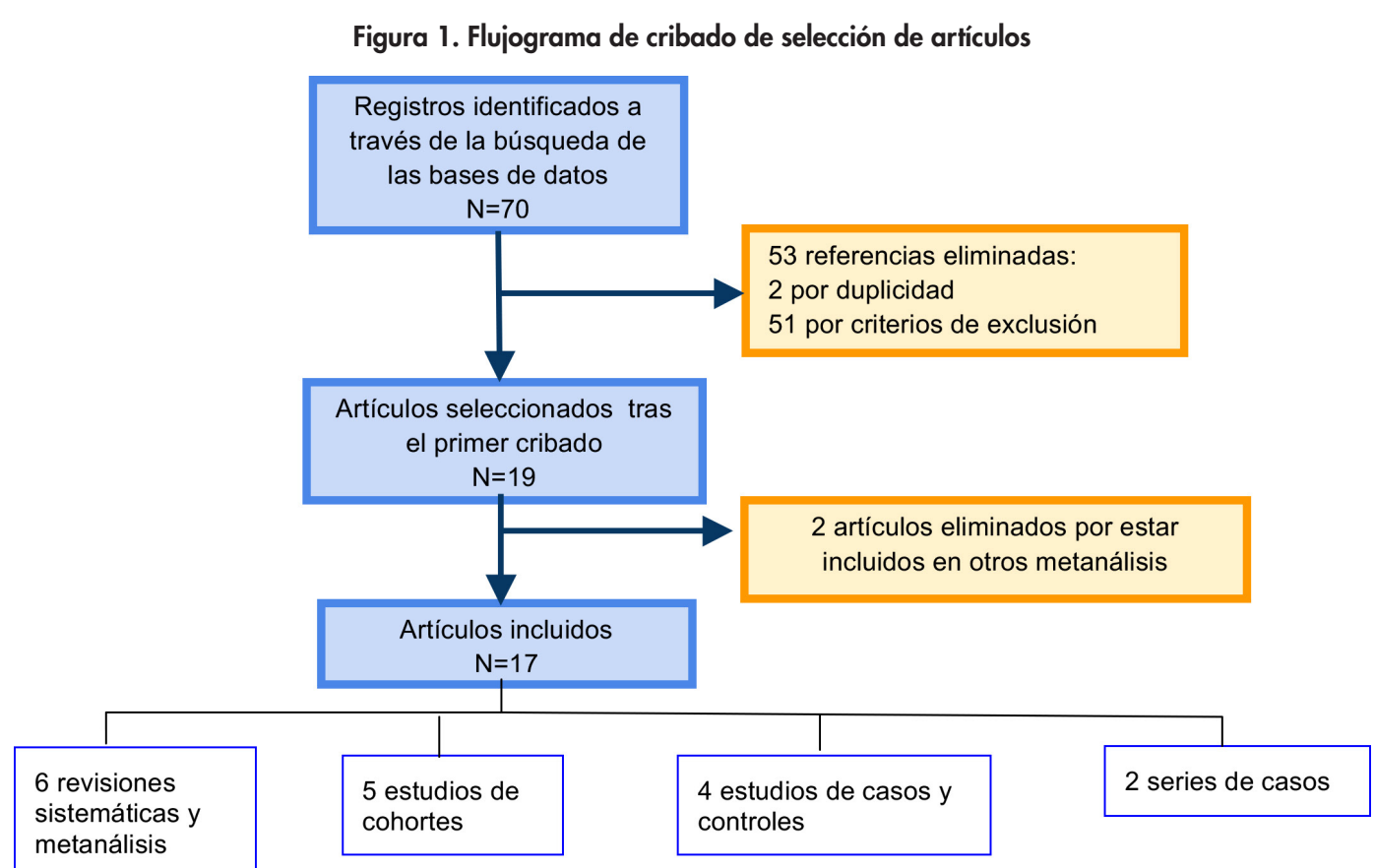

\section{Calidad}

Se evaluó la calidad de los artículos seleccionados mediante la declaración PRISMA para las revisiones sistemáticas y metaanálisis, y la declaración STROBE para los estudios observacionales (cohortes y casos y controles). En las 6 revisiones sistemáticas y metanálisis analizados se obtuvo una puntuación mínima del cuestionario PRISMA de 13 y máxima de 27 (sobre un total de 27 puntos posibles). Tres de las revisiones sistemáticas obtuvieron una calidad $<80 \%{ }^{13,17,19}$.

En los 10 estudios observacionales, la puntuación del cuestionario STROBE osciló entre 17 y 21 (sobre un total de 22 puntos posibles). Sólo uno de ellos ${ }^{16}$ obtuvo una puntuación inferior al $80 \%$.

Los resultados detallados de la calidad de los estudios aparecen en los anexos I y II. 


\section{Resultados}

Suárez Baena et al ${ }^{13}$ realizaron una revisión sistemática con el objetivo de determinar la relación entre el cáncer vesical y la exposición a determinadas sustancias en el ámbito laboral, clarificar aquellas profesiones con mayor riesgo y si éste presenta diferencia entre géneros. Tras el análisis de datos concluyeron que existe relación significativa entre cáncer vesical y determinadas profesiones expuestas a aminas e hidrocarburos aromáticos policíclicos, estando los resultados limitados por las carencias propias del diseño de cada estudio (sesgos no controlados de tabaco o enfermedades endémicas por schistosoma). Las profesiones con mayor riesgo de desarrollar cáncer vesical son las relacionadas con la industria de hierro, acero y colorantes (ver anexo IV), con predominio del sexo masculino en las poblaciones estudiadas, probablemente atribuible a que la mayoría de los puestos en el sector industrial están ocupados por hombres y por lo tanto, no es posible determinar evidencia científica que relacione el género con mayor sensibilidad a desarrollar cáncer vesical por exposición laboral.

En la revisión de Al-Zalabani et $a l^{17}$ se incluyeron 82 metanálisis, de los cuales 21 fueron seleccionados como los más completos para un solo factor de riesgo, y 5 fueron combinados en dos meta meta análisis (MMAs), dando información ambos sobre 36 factores de riesgo. La probabilidad de causa (POC) varió de un 9 a un 68\% entre los factores de estilo de vida y entre un 4 y $42 \%$ para exposiciones ocupacionales. Los factores ocupacionales se consideran el segundo factor de riesgo más importante para el desarrollo de cáncer de vejiga después del tabaco. Trabajadores expuestos a aminas aromáticas, hidrocarburos aromáticos policíclicos, tabaco y humo de tabaco, productos de combustión y metales pesados presentan mayor riesgo. Para minimizar el efecto confusor del hábito tabáquico, sólo se seleccionaron las estimaciones más ajustadas de cada metanálisis.

En el metanálisis de $M u n d t$ et $a l^{18}$ se pretendía evaluar si el riesgo de cáncer está aumentado entre trabajadores expuestos a bitumen (asfalto). Se incluyeron resultados del estudio multicéntrico IARC de ocho países europeos. También incluyeron resultados de 11 estudios de cohortes y 7 estudios de certificados de muerte llevados a cabo en Estados Unidos y Europa. Asimismo, incluyeron resultados de 26 estudios casos-control. La evidencia epidemiológica no reportó un incremento del riesgo de cáncer de vejiga asociado con la exposición a bitumen. El análisis sobre el cáncer de vejiga estaba basado en 23 estudios: meta-RR=1,09, (IC95\% 0,93-1,27). Se observó una heterogeneidad moderada cuando todos los estudios se incluían ( $I 2=47,5 \%, \mathrm{p}=0,006)$. Teniendo en cuenta que no se consideró la información sobre el hábito tabáquico y otras exposiciones ocupacionales por los investigadores, no se evidenció un aumento del riesgo de cáncer de vejiga en trabajadores expuestos a bitumen.

Myong et $a l^{19}$ llevaron a cabo una revisión sistemática con el objetivo de realizar un estudio exhaustivo y sugerir posibles criterios de indemnización para los cánceres ocupacionales en los pintores de Korea. La información evaluada en esta revisión fue tomada de reportes científicos de carcinógenos de la IARC y de la Industrial Injuries Advisory Council (IIAC), así como de literatura existente sobre exposición ocupacional en pintores de Korea y de investigaciones epidemiológicas de casos de cáncer en pintores de Korea. Los resultados de la evidencia científica de carcinógenos contaron con una serie de metaanálisis que incluyen 11 cohortes y 28 caso-control, los cuales mostraron un meta-RR para el cáncer de vejiga de 1,24 (IC 95\%: 1,16-1,33). Sin embargo, la IARC no especificó qué componente de la pintura aumenta significativamente la incidencia o mortalidad por cáncer de vejiga (como cromato, hidrocarburos aromáticos, benceno y otros agentes). Asimismo, nombró que ciertos factores de confusión, tales como el tabaco, pueden ser unas de las razones por las cuales había una alta incidencia de cáncer de vejiga en pintores. Por estos motivos, concluyeron que los riesgos de la exposición ocupacional para el cancer de vejiga de pintores en Korea no está definida actualmente.

En el metaanálisis de Boniol et $a l^{20}$ se evaluó la asociación entre la exposición ocupacional en la industria del caucho y el incremento del riesgo de cáncer. Se incluyeron 
46 estudios de cohortes y 59 de caso-control. En el cáncer de vejiga, uno de los más investigados ( 54 estudios), se encontró un riesgo aumentado en relación a la exposición ocupacional de caucho, con un riesgo relativo estandarizado (SRR) y IC del 95\% de 1,36 (1,18-1,57). Análisis estratificados mostraron un riesgo más bajo para los trabajadores contratados más recientemente, después de 1960 y 1970, con un SRR (IC 95\%) de 1,06 $(0,66-1,71)$ y $0,81(0,40-1,64)$ respectivamente.

El metaanálisis efectuado por Cumberbatch et al tuvo como objetivo perfilar los riesgos de cáncer de vejiga en la actualidad, debido a la frecuencia de aparición de este tipo de cáncer en relación a la exposición a carcinógenos profesionales. Se identificaron 25 artículos que contaban con 702.941 personas. El riesgo significativo más alto de cáncer de vejiga lo tuvieron las profesiones relacionadas con procesos químicos (RR 1,87, IC 95\% 1,50-2,34), caucho (RR 1,82, IC 95\% 1,40-2,38) y trabajadores del tinte (RR 1,80, IC 95\% 1,07-3,04). Otras profesiones con riesgo aumentado de forma significativa se encuentran recogidas en el anexo IV. Respecto a la tasa de mortalidad específica por enfermedad (DSM), 3 profesiones tuvieron un aumento significativo del riesgo, los electricistas (RR 1,49, IC 95\% 1,19-1,87), las relacionadas con procesos químicos (RR 1,35, IC 95\% 1,091,68) y transportistas (RR 1,15, IC 95\% 1,03-1,28). Los autores sugirieron que el perfil de ocupación de riesgo para el cáncer de vejiga difiere de aquellas en riesgo de morir por el cáncer de vejiga.

Latifovic et $a l^{21}$ estudiaron la relación entre la exposición ocupacional a las emisiones de motores diésel y gasolina y el desarrollo de cáncer de vejiga. Llevaron a cabo un estudio de casos-controles con una muestra de 1.360 controles y 658 casos. Se ajustó la matriz de trabajadores expuestos en tres dimensiones: exposición (baja, media o alta), frecuencia y fiabilidad. También se ajustó por posibles factores de confusión como exposición al tabaco, historia residencial, alimentación, etc. Se encontró que los expuestos alguna vez a altas concentraciones de diésel tenían un riesgo de cáncer de vejiga aumentado (OR 1,64, 0,87-3,08) pero este resultado no fue significativo, y aquellos con $>10$ años de exposición a diésel a altas concentraciones tuvieron el doble de aumento de riesgo (OR 2,45, 1,04-5,74). Respecto a la gasolina, no se observa relación estadísticamente significativa, pero sí se observó un aumento de cáncer de vejiga en el análisis de subgrupos (gasolina en los expuestos en más de un 30\% del tiempo de exposición (OR 1,59, 1,04$2,43)$ respecto a los no expuestos, pero solo a aquellos que adicionalmente nunca habían estado expuestos a diésel).

M. Allen et $a l^{22}$ realizaron un estudio de cohortes con el propósito de evaluar la incidencia general de cáncer en los mineros de Minnesota al trabajar con un mineral de bajo grado (taconita) compuesto por un $27 \%$ de hierro y un $51 \%$ de sílice, en cuyo procesamiento se liberan partículas minerales. Se evaluó la incidencia de cáncer en una cohorte de 40.720 mineros que trabajaron entre 1937 y 1983 y que se siguieron hasta el diagnóstico, fecha de la muerte o fecha de fin de estudio. Los ratios estandarizados de incidencia (SIR) con un IC del 95\% se estimaron comparando la incidencia de cáncer en la población general con la incidencia de cáncer en el Minnesota Cancer Surveillance en función del sexo, edad y periodo de tiempo. Se ajustó por migración fuera del estado y se realizó un análisis probabilístico de sesgo para los pacientes fumadores. El SIR para cáncer de vejiga resultó aumentado, pero ajustado por tabaquismo, se atenuaba el efecto (SIR 1,0 95\% 0,8-1,1), resultando éste no estadísticamente significativo.

Tomioka et $a^{23}$ plantearon un estudio de cohortes históricas para evaluar el riesgo de cáncer asociado a la exposición ocupacional a bencidina y/o beta-naftilamina (presentes en pigmentos y tintes) en los trabajadores de una fábrica de químicos. Se incluyó a un total de 224 hombres expuestos que se siguieron desde 1953 a 2011. Los sujetos se dividieron en grupos de corta y larga exposición basados en la duración de la exposición (DOE). Los SIR específicos para cáncer se calcularon usando como referencia los SIR nacionales y regionales, y se tuvo en cuenta la historia de tabaquismo. Se identificó un aumento de SIR para el cáncer de vejiga $(4,70,95 \%$ CI 1,89-9,67) y un aumento de riesgo en los sujetos expuestos respecto a ambas poblaciones de referencia general y regional, así como un aumento de riesgo significativo en los grupos de corta $(5,58,95 \% 1,10-16,30)$ 
y larga exposición (4,20, 95\% IC 1,14- 10,76). Tras ajustar por tabaco, exposición adicional a bis-clorometil éter y edad de la primera exposición, se observó que la incidencia de cáncer de vejiga no se vio afectada por la DOE (explicable posiblemente por el pequeño número de casos de cáncer de vejiga de la muestra), no observándose un aumento significativo para el grupo de exposición de larga duración (HR 1,69 95\% CI 0,37-7,67).

Hadkhale et $a l^{24}$ realizaron un estudio de casos y controles en países nórdicos (Finlandia, Islandia, Noruega y Suecia). Se trabajó con una muestra de 113.343 casos de cáncer de vejiga, frente a 566.712 controles. El objetivo era establecer si existía relación entre la exposición ocupacional a diferentes disolventes y el riesgo de cáncer de vejiga utilizando una matriz nórdica de exposición laboral (NOCCA JEM). No disponían de información acerca del hábito tabáquico. Una vez hecho el análisis, se encontró que existía un incremento del riesgo estadísticamente significativo con Hazard Ratio (HR) > 1,10 para tricloroetileno, tolueno y benceno a alto nivel de exposición y para el percloroetileno a un nivel de exposición medio (tricloroetileno: HR:1,23 (IC95\% 1,121,40); tolueno: HR: 1,2 (IC95\%: 1,00-1,38); benceno: HR:1,16, (IC 95\% 1,04-1,31); percloroetileno HR 1,12, IC95\% 1,02-1,23). Se concluyó que la exposición a tricloroetileno estaba asociado de forma significativa con riesgo aumentado de cáncer de vejiga, a nivel alto de exposición (limpieza en seco y trabajadores de aeronaves y aeroespaciales). Asimismo, también se encontró asociación con exposición a percloroetileno, benceno y tolueno.

Koutros et al ${ }^{25}$ llevaron a cabo un estudio de cohortes prospectivo con datos del AHS (Agricultural Health Study), donde estudiaron una gran cohorte de aplicadores de pesticidas con el fin de evaluar la asociación entre distintos pesticidas y riesgo de cáncer de vejiga. El análisis incluyó todos los cánceres de vejiga incidentes diagnosticados desde 1993 hasta el 31 de diciembre de 2011. Se observó aumento del riesgo de cáncer de vejiga entre los usuarios de herbicidas como bentazon ( $R R=1,55$, IC95\%: 1,10-2,19) o bromoxinil (RR=1,51, IC95\%: 1,04-2,20) (ver Anexo IV). Al estratificar por tabaquismo, se observó una tendencia positiva para imazetapir (RR en el cuartil 4 vs no expuestos=3,03, IC95\%: 1,46-6,29, P-trend=0,004) entre los no fumadores. Se concluyó un aumento de riesgo de cáncer de vejiga con dos herbicidas compuestos de aminas aromáticas, que son imazetapir e imazaquin. La relación del cáncer de vejiga e imazetapir era más aparente entre los no fumadores.

Farzaneh et $a l^{1}$ realizaron un estudio de caso-control en Yazd (Irán) para establecer la relación entre ocupación profesional y riesgo de cáncer de vejiga. La muestra contó con 400 personas, 200 casos con cáncer vesical y 200 controles sanos de la provincia de Yazd. La recogida de datos tuvo lugar mediante cuestionarios y entrevistas a los casos y a los controles. El cuestionario incluyó perfil sociodemográfico, socioeconómico, estilo de vida, historia familiar, uso de drogas, historial médico, irradiación en parte inferior del cuerpo, exposición a químicos y uso de tinte de pelo. Los trabajos se clasificaron en función de la exposición a carcinógenos conocidos, dividiéndolos en trabajos de alto y bajo riesgo. Los trabajos de alto riesgo estuvieron constituidos por industria textil, metalúrgica y química. La frecuencia de cáncer de vejiga fue significativamente superior en los trabajos de alto riesgo, con una OR y un IC 95\% de 3,24 (1,99-5,29). En el presente estudio se observó el mayor incremento del riesgo de cáncer de vejiga en trabajadores del metal comparados con el grupo control, contando con 12 eventos entre los casos y 3 entre los controles, con una OR (IC 95\%) de 6,45 (1,76-23,68).

MacLeod et al ${ }^{26}$ llevaron a cabo un estudio de cohortes retrospectivo en Canadá donde el objetivo era evaluar la asociación entre la profesión de soldador y el riesgo de padecer diferentes cánceres por la exposición a una serie de carcinógenos. La cohorte de soldadores la componen 12.845 hombres. Además, hubo 87.460 soldadores ocasionales (no tienen la soldadura como actividad principal pero pueden verse ocasionalmente implicados en actividades de esa índole). El grupo de referencia lo constituyeron los no soldadores, algunos de ellos habían sido trabajadores 'blue-collar', siendo los obreros no implicados en trabajos de soldadura pero empleados en el comercio, transporte y ocupaciones relacionadas. 
Se comparó el grupo de soldadores con el grupo de referencia de no soldadores con HR a IC al 95\% y ajustado por grupo de edad, región y nivel de educación. Aparecieron 100 casos de cáncer de vejiga, con un HR (IC 95\%) de 1,40 (1,15-1,70). Se comparó también el grupo de soldadores con el grupo de referencia de no soldadores en trabajos 'blue-collar' únicamente, ajustado por grupo de edad y región, teniendo como resultado un HR (IC 95\%) de 1,47 (1,21-1,79). Por lo tanto, el estudio muestra evidencias que la exposición a la soldadura puede contribuir a incrementar un $40 \%$ el riesgo de cáncer de vejiga en soldadores.

Por otra parte, en el grupo de soldadores ocasionales acontecieron 515 casos de cáncer de vejiga. Igual que anteriormente, se comparó con el grupo de referencia de no soldadores y con el grupo de no soldadores con trabajos 'blue-collar', obteniendo HR (IC 95\%) de 0,99 (0,90-1,08) y 1,03 (0,94-1,13) respectivamente. Por tanto, en comparación con los soldadores, no se detectó un riesgo incrementado de cáncer de vejiga en soldadores ocasionales.

Callahan et $a l^{16}$ llevaron a cabo un estudio de cohortes a partir de registros históricos del Local No. 161 (St Louis) de la Unión Internacional de Trabajadores de Lavandería, Tintorería y Dye House. En el análisis de la exposición al tetracloroetileno, se observa una relación de exposición-respuesta para el cáncer de vejiga (HR para exposición media = 4,2; IC del 95\% = 0,7-24,5 y HR para exposición alta $=9.2 ;$ IC 95\% = 1,1-76,7 vs. no exposición; $\mathrm{P}$ trend $=0,08)$, con aumento del riesgo del mismo. La falta de información sobre el hábito de fumar de los sujetos es una limitación del estudio.

Colin et $a l^{27}$ llevaron a cabo un estudio de casos y controles anidados en una cohorte. Ésta incluyó 22.795 trabajadores varones de seis fábricas francesas productoras de acero, empleados durante al menos 1 año en la misma fábrica. Los resultados de este estudio sugieren que la exposición a fluidos metalúrgicos puros se asocia con un mayor riesgo de cáncer de vejiga entre 5 y 25 años después de la exposición. Se observó un aumento muy marcado de la OR en relación con la duración de la exposición a los estos fluidos metalúrgicos puros $(\mathrm{OR}=1,13(1,02-1,25))$ y con la duración de la exposición ponderada en frecuencia a los mismos $(\mathrm{OR}=1,44(0,97-2,14))$. Estos resultados son válidos tras ajustar por la exposición al tabaquismo y a hidrocarburos policíclicos aromáticos (HAP). La OR también aumentó con la exposición a los fluidos metalúrgicos solubles y sintéticos, pero sin significación estadística, así como a exposiciones a fluidos metalúrgicos con anterioridad.

Strand et $a t^{28}$ realizaron un estudio de serie de casos compuesta por 8.378 hombres y mujeres civiles empleados por la Royal Norwegian Navy entre 1950 y finales de 2005. Los diagnósticos de cáncer y las fechas de diagnóstico se obtuvieron mediante la vinculación al Registro de Cáncer de Noruega. Todos los miembros de la cohorte fueron seguidos por incidencia de cáncer y muerte. Entre el subgrupo de trabajadoras formado por limpiadoras femeninas, hubo un aumento estadísticamente significativo de cáncer de vejiga, mostrando un SIR de 2,33. La mortalidad por todas las causas fue menor de lo esperado para los hombres, con un SMR (índice de mortalidad estandarizado) de 0,92 (IC 95\% 0,88-0,96) y más parecida a la tasa de referencia para las mujeres, con un SMR de 0,95 (IC 95\% 0,88-1,01).

Hadkhale et $a \mathbf{l}^{29}$ realizaron un estudio de serie de casos con el fin de conocer las profesiones más relacionadas con la aparición de cáncer de vejiga. Para ello se utilizó el Registro del Cáncer Ocupacional Nórdico (NOCCA), que comprende datos de incidencia de cáncer de hasta 45 años por categorías ocupacionales. La cohorte consta de 14,9 millones de personas de los cinco países nórdicos (Dinamarca, Finlandia, Islandia, Noruega y Suecia) de 30 a 64 años, de donde se obtuvieron los casos. Debido a la falta de información sobre el hábito tabáquico en todas las categorías ocupacionales, se estimó una prevalencia de tabaquismo indirecto en los grupos profesionales de los casos incidentes de cáncer de pulmón de los datos NOCCA. Los SIR ajustados al tabaquismo más altos se observaron en deshollinadores (SIR 1,29, IC 95\% 1,05-1,56), camareros $(1,22,1,07-1,38)$, peluqueros $(1,14,1,02-1,26)$, cocineros y mayordomos $(1,12,1,01-$ $1,25)$, impresores $(1,11,1,04-1,18)$ y marineros $(1,09,1,03-1,14)$. 


\section{DISCUSIÓN}

Los resultados que exponen los estudios analizados en esta revisión sistemática revelan una clara relación causa-efecto entre distintas sustancias empleadas en diferentes sectores industriales y el desarrollo de cáncer de vejiga.

En esta revisión se han recuperado 17 estudios. Al aplicar a estos artículos los parámetros establecidos por la Declaración STROBE o PRISMA, según se trataran de estudios observacionales o revisiones sistemáticas/metanálisis, respectivamente, se ha podido determinar que la mayoría cumplen con la mayor parte de los ítems.

A continuación detallamos las principales limitaciones de los estudios de menor calidad: el estudio de $A l$-Zalabani et $a l^{17}$ presenta como principal limitación, no especificar datos sobre riesgos de sesgos. En el caso de la revisión llevada a cabo por Suárez-Baena et $a l^{13}$, aunque se comenta la posibilidad de que algunos estudios estén limitados por sesgos (schistosomiasis, fumadores) no se aportan datos concretos sobre este riesgo ni los métodos utilizados para evaluarlo. Tampoco se mencionan métodos adicionales de análisis de los resultados. El estudio de Myong et al ${ }^{19}$ tiene como limitaciones cualitativas, no presentar una estrategia de búsqueda con los límites utilizados, así como no mencionar la metodología para la extracción de datos de de las distintas publicaciones. De la misma manera, no se han descrito los métodos utilizados para evaluar el riesgo de sesgo en los estudios individuales, ni las limitaciones de la revisión. El estudio llevado a cabo por Callaban et al ${ }^{16}$ presenta un relativo pequeño tamaño muestral y no se ajustó por hábito tabáquico, con el consiguiente sesgo que puede conllevar.

Al analizar los resultados, se advierte que en 8 estudios, se obtuvieron datos que confirmaban la existencia de una relación causal entre hidrocarburos policíclicos y aminas aromáticas con el cáncer de vejiga ${ }^{1,13,17,18,23,24,27,28}$. De entre ellos, cabe destacar el estudio de Tomioka et $a l^{23}$ en el que se evidenció una relación entre la exposición a beta-naftilamina y bencidina con el cáncer de vejiga que era independiente de la dosis, edad del personal expuesto y tiempo de exposición. En el mismo sentido, Koutros et al ${ }^{25}$, observaron un riesgo aumentado de cáncer de vejiga con los herbicidas aromáticos imazetapir e imazaquin, así como con otros pesticidas organoclorados.

En el estudio de Latifovic et $a l^{21}$ se evidencia la existencia de aumento de riesgo de padecer cáncer de vejiga con la exposición a altas concentraciones de emisiones diésel (óxido de carbono, nitrógeno y sulfuro) principalmente con duración de la exposición ocupacional mayor a 10 años. No sucede lo mismo con los trabajadores expuestos a emisión de motores de gasolina, donde no se observa una relación estadísticamente significativa con el desarrollo de cáncer de vejiga excepto en el análisis de subgrupos.

Asimismo, en dos estudios observacionales se estableció una asociación causal entre distintos disolventes ${ }^{16,24}$ y el ulterior desarrollo de cáncer de vejiga, destacando la influencia del tricloroetileno y el tetracloroetileno presente en varios estudios ${ }^{19,16,17,1}$. También se encontró asociación con la exposición a percloroetileno, benceno y tolueno ${ }^{17}$.

Las distintas profesiones en las que podemos encontrar este tipo de sustancias son muy numerosas: lavanderías, tintorerías, limpieza en seco, industria del metal, industria aeronáutica, textil o pinturas (TCE, percloroetileno), agricultores (aminas aromáticas como imazetapir o imazaquin), industria textil, peluqueros (aminas aromáticas y compuestos nitrosos aromáticos), trabajadores de imprenta (pigmentos y disolventes), industria metalúrgica (presencia de hidrocarburos aromáticos policíclicos en aceites minerales), soldadores, deshollinadores ${ }^{13}$.

A propósito de la profesión de soldador, en el estudio llevado a cabo por McLeod et al (25), se demostró riesgo superior de padecer cáncer de vejiga en estos trabajadores (concretamente, el riesgo aumenta un 40\%). Sin embargo, dicho riesgo no se vio incrementado en soldadores ocasionales. 
De hecho, en el estudio llevado a cabo por Farzaneh et al ${ }^{1}$, nombra a los profesionales del metal como los que tienen un riesgo más alto de desarrollar cáncer de vejiga. Dentro de la profesión del metal se incluye soldadura, corte y fabricación de puertas y ventanas. Este aumento del riesgo es probablemente debido a la exposición de humos y algunos metales pesados y fluidos de metales; aunque identificar la causa exacta es difícil por la diferencia en la composición de estos humos y fluidos metalúrgicos ${ }^{1,27}$.Otras de las profesiones que establece con más riesgo son trabajadores del textil, conducción, agricultura y construcción.

También se establece relación entre los trabajadores del sector del caucho, donde se encontró un riesgo aumentado de padecer cáncer de vejiga en relación a la exposición ocupacional a esta sustancia ${ }^{8,13,20}$. En el estudio llevado a cabo por Allen et $a l^{22}$ en los mineros expuestos a taconita (variedad de hierro bandeado) se halló un aumento del SRI para cáncer de vejiga; sin embargo, se atenuaba el efecto ajustado por tabaquismo. En el mismo sentido, en el estudio de $M u n d t$ et $a l^{18}$ en trabajadores expuestos a bitumen o humos de bitumen (pavimentadores), no se evidenció un aumento de riesgo de cáncer de vejiga.

Teniendo en cuenta que el tabaco es el principal agente causal en la aparición del cáncer de vejiga ${ }^{6}$, consideramos relevante que estos estudios hayan tenido en cuenta la exposición al tabaco en los trabajadores como posible factor de confusión, ajustando sus resultados para minimizar el impacto que pudiera tener el hábito tabáquico ${ }^{1,17.21-23,24,25,27-29}$. En otros estudios ${ }^{13,19,20,26}$, en cambio, los investigadores no mencionaron si tuvieron en cuenta dicho factor o si ajustaron sus resultados en base a ello ${ }^{8,16,18}$, por lo que sus resultados deben analizarse con cautela. Tampoco hemos observado resultados que orienten a una mayor incidencia de cáncer de vejiga ajustado por sexo, siendo escasas las referencias encontradas en este sentido en los estudios revisados.

\section{CONCLUSIONES}

Tras haber revisado los estudios seleccionados, varios con máximo grado de evidencia (3 de los meta-análisis con una calidad $>80 \%$ ), se puede concluir que existe vinculación probada entre la exposición ocupacional a determinadas sustancias, fundamentalmente aminas aromáticas e hidrocarburos policíclicos y cáncer de vejiga. Respecto a otras sustancias menos estudiadas (motores diésel y gasolina, mineros del carbón-taconita) aunque se observa una tendencia a la mayor incidencia de cáncer de vejiga en trabajadores expuestos, son necesarios más estudios, y se requiere más información, y de más calidad, que permita establecer resultados concluyentes.

Del mismo modo, al ser el cáncer vesical el resultado final de la combinación variable de los factores de riesgo constitucionales y ambientales (edad, sexo, polimorfismos genéticos, exposición a tabaco, exposición laboral) sería preciso conocer la medida en que estos factores influyen en los resultados de los estudios para evitar incurrir en sesgos.

Los cambios legislativos y las mejoras en el lugar del trabajo así como las medidas de seguridad ya están teniendo impacto en la incidencia del cáncer de vejiga provocando cambios demográficos como se evidencia en algunos de los estudios revisados, donde se observa una disminución del riesgo respecto a series históricas, lo que reitera aún más la importancia de que se apliquen estas políticas.

No obstante, a pesar de la escasa evidencia disponible respecto a ciertas sustancias, y a las limitaciones propias de cada estudio, creemos necesario establecer programas de vigilancia y seguimiento de los trabajadores respecto a las sustancias de probada relación con el cáncer de vejiga así como las susceptibles de aumentar su incidencia que hemos evaluado en esta revisión sistemática. 


\section{AGRADECIMIENTOS}

Agradecemos la orientación y colaboración del Dr. Luis M. ${ }^{a}$ Sánchez Gómez, así como a Virginia Jiménez Canales por su disposición y ayuda para la realizaciónde este trabajo.

\section{BIBLIOGRAFÍA}

1. Farzaneh F, Mehrparvar AH, Lotfi MH. Occupations and the Risk of Bladder Cancer in Yazd Province: A Case-Control Study. Int J Occup Environ Med. 2017;8(4):191-8.

2. Araujo-Alvarez JM, Trujillo-Ferrara JG. De Morbis Artificum Diatriba. Salud Pública México. 2002;44:362370.

3. Sofronievska M, Ristovski S, Kochubovski M, Glavinov A. Environmental influence in the incidence of bladder cancer.J Environ Prot Ecol. 2015;16:733-739.

4. Asociación Española Contra el Cáncer [Internet]. Madrid:AECC;[consultado el 15 noviembre de 2019]. Disponible en: https://www.aecc.es/es

5. SEOM:Sociedad Española de Oncología Médica. Las cifras del cáncer en España 2018 [Internet]. Madrid: SEOM;[consultado el 15 de noviembre de 2019]. Disponible en: https://seom.org/es/noticias/106525-lascifras-del-cancer-en-espana-2018

6. Nesi G, Galli I, Amorosi A, Santi R. Environment and urinary bladder cancer. A historical perspective. Pol J Pathol. 2019;70:21-5.

7. Lakkis NA, Adib SM, Hamadeh GN, El-Jarrah RT, Osman MH. Bladder Cancer in Lebanon: Incidence and Comparison to Regional and Western Countries. Cancer Control. 2018;25(1):1-7.

8. Cumberbatch MGK, Cox A, Teare D, Catto JWF. Contemporary Occupational Carcinogen Exposure and Bladder Cancer: A Systematic Review and Meta-analysis. JAMA Oncol. 2015;1(9):1282.

9. España. Real Decreto 665/1997, de 12 de mayo, sobre la protección de los trabajadores contra los riesgos relacionados con la exposición a agentes cancerígenos durante el trabajo. Boletín Oficial del Estado de 24 de mayo de 1997, número 124.

10. Cogliano VJ, Baan R, Straif K, Grosse Y, Lauby-Secretan B, El Ghissassi F, et al. Preventable Exposures Associated With Human Cancers. JNCI J Natl Cancer Inst. 2011;103(24):1827-39.

11. Kogevinas M, 't Mannetje A, Cordier S, Ranft U, González CA, Vineis P, et al. Occupation and bladder cancer among men in Western Europe. Cancer Causes Control. 2003;14(10):907-14.

12. Siemiatycki J, Richardson L, Straif K, Latreille B, Lakhani R, Campbell S, et al. Listing Occupational Carcinogens. Environ Health Perspect. 2004;112(15):1447-59.

13. Suárez-Baena B, Encarnación-Encarnación N, Valladares-Lobera B. Revisión bibliográfica de cáncer vesical de origen laboral. Med Segur Trab. 2015;61(239):295-310.

14. PRISMA [Internet]. [revisado el 21 de noviembre de 2019]. Disponible en: http://prisma-statement.org/ prismastatement/Checklist.aspx

15. STROBE Statement: Available checklists [Internet]. [revisado el 21 de noviembre de 2019].Disponible en: https://www.strobe-statement.org/index.php?id=available-checklists

16. Callahan CL, Stewart PA, Blair A, Purdue MP. Extended Mortality Follow-up of a Cohort of Dry Cleaners: Epidemiology. 2019;30(2):285-90.

17. Al-Zalabani AH, Stewart KFJ, Wesselius A, Schols AMWJ, Zeegers MP. Modifiable risk factors for the prevention of bladder cancer: a systematic review of meta-analyses. Eur J Epidemiol. 2016;31(9):811-51.

18. Mundt KA, Dell LD, Crawford L, Sax SN, Boffetta P. Cancer Risk Associated With Exposure to Bitumen and Bitumen Fumes: An Updated Systematic Review and Meta-Analysis. J Occup Environ Med. 2018;60(1):6-54.

19. Myong J-P, Cho Y, Choi M, Kim H-R. Overview of occupational cancer in painters in Korea. Ann Occup Environ Med. 2018;30(1):10.

20. Boniol M, Koechlin A, Boyle P. Meta-analysis of occupational exposures in the rubber manufacturing industry and risk of cancer. Int J Epidemiol. 2017;46(6):1940-7.

21. Latifovic L, Villeneuve PJ, Parent M-É, Johnson KC, Kachuri L, the Canadian Cancer Registries Epidemiology Group. Bladder cancer and occupational exposure to diesel and gasoline engine emissions among Canadian men. Cancer Med. 2015;4(12):1948-62. 
22. Allen EM, Alexander BH, MacLehose RF, Nelson HH, Ramachandran G, Mandel JH. Cancer incidence among Minnesota taconite mining industry workers. Ann Epidemiol. 2015;25(11):811-815.

23. Tomioka K, Obayashi K, Saeki K, Okamoto N, Kurumatani N. Increased risk of lung cancer associated with occupational exposure to benzidine and/or beta-naphthylamine. Int Arch Occup Environ Health. 2015;88(4):455-65.

24. Hadkhale K, Martinsen JI, Weiderpass E, Kjaerheim K, Sparen P, Tryggvadottir L, Lynge E, Pukkala E. Occupational exposure to solvents and bladder cancer: A population-based case control study in Nordic countries. Int J Cancer. 2017;140(8):1736-46.

25. Koutros S, Silverman DT, Alavanja MC, Andreotti G, Lerro CC, Heltshe S, et al. Occupational exposure to pesticides and bladder cancer risk. Int J Epidemiol. 2016;45(3):792-805.

26. MacLeod JS, Harris MA, Tjepkema M, Peters PA, Demers PA. Cancer Risks among Welders and Occasional Welders in a National Population-Based Cohort Study: Canadian Census Health and Environmental Cohort. Saf Health Work. 2017;8(3):258-66.

27. Colin R, Grzebyk M, Wild P, Hédelin G, Bourgkard È. Bladder cancer and occupational exposure to metalworking fluid mist: a counter-matched case-control study in French steel-producing factories. Occup Environ Med. 2018;75(5):328-36.

28. Strand LA, Martinsen JI, Rudvin I, Fadum EA, Borud EK. Cancer incidence and all-cause mortality among civilian men and women employed by the Royal Norwegian Navy between 1950 and 2005. Cancer Epidemiol. 2018;57:1-6.

29. Hadkhale K, Martinsen JI, Weiderpass E, Kjærheim K, Sparén P, Tryggvadóttir L, et al. Occupational variation in bladder cancer in Nordic males adjusted with approximated smoking prevalence. Acta Oncol. 2019;58(1):29-37.

30. Cumberbatch MGK, Cox A, Teare D, Catto JWF. Contemporary Occupational Carcinogen Exposure and Bladder Cancer: A Systematic Review and Meta-analysis. JAMA Oncol. 2015;1(9):1282-90.

31. Boniol M, Koechlin A, Świątkowska B, Sorahan T, Wellmann J, Taeger D, et al. Cancer mortality in cohorts of workers in the European rubber manufacturing industry first employed since 1975. Ann Oncol. 2016 May;27(5):933-41.

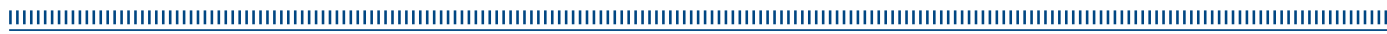




\section{LISTADO DE ABREVIATURAS}

- MeSH: Thesaurus desarrollado por la U.S. National Library of Medicine

- LILACS: Literatura Latinoamericana y del Caribe en Ciencias de la Salud

- IBECS: Índice Bibliográfico Español en Ciencias de la Salud

- STROBE: Strengthening the reporting of Observational studies in Epidemiology

- PRISMA: Preferred Reporting Items for Systematic reviews and Meta-Analyses

- WOS: Web Of Science

- IARC: Agencia Internacional para la Investigación del Cáncer

— IIAC: Industrial Injuries Advisory Council

- OR: Odds Ratio

- HR: Hazard Ratio

- IC95\%: Intervalo de Confianza del 95\%

- RR: Riesgo Relativo

- $\mathrm{P}_{\text {trend }}: \mathrm{p}$ de tendencia

- POC: Probabilidad de causa

- SRR: Riesgo relativo estandarizado

- SIR: Índice de incidencia estandarizado

- SMR: Índice de mortalidad estandarizado

- MMA: meta metaanálisis

- Meta-RR: meta riesgo relativo

- BZ/BNA: bencidina/beta- naftilamina

- DOE: Duración de la exposición

- HAP: hidrocarburos policíclicos aromáticos

— DSM: tasa de mortalidad específica por edad 


\section{ANEXOS}

Anexo I. Calidad de la evidencia estudios observacionales

\begin{tabular}{|c|c|c|c|c|c|c|c|c|c|c|c|c|c|c|c|c|c|c|c|c|c|c|c|c|}
\hline & & & & & & & & & & & EM & S D D & DECI & LAR & ACIÓ & SN ST & TROI & $\mathrm{BE}$ & & & & & & \\
\hline AU'TOR Y AÑO & 1 & 2 & 3 & 4 & 5 & 6 & 7 & 8 & 9 & 10 & & 11 & 12 & 13 & 14 & 15 & 16 & 17 & 18 & 19 & 20 & 21 & 22 & $\begin{array}{l}\text { TOTAL } \\
\text { (\%) }\end{array}$ \\
\hline $\begin{array}{l}\text { Hadkhale et } \\
\text { al } 2016\end{array}$ & + & + & + & + & + & + & + & + & + & + & & + & + & + & + & + & + & & + & + & + & + & & $\begin{array}{c}20 \\
(90,9 \%)\end{array}$ \\
\hline $\begin{array}{l}\text { Koutros et } \\
\text { al. } 2015\end{array}$ & & + & + & + & + & + & + & + & + & + & & + & + & + & + & + & + & + & + & + & + & & + & $\begin{array}{c}21 \\
(95,4 \%)\end{array}$ \\
\hline $\begin{array}{l}\text { MacLeod et } \\
\text { al. } 2017\end{array}$ & + & + & + & + & + & + & + & - & + & + & & + & + & + & + & + & + & & + & + & + & + & + & $\begin{array}{c}20 \\
(90,9 \%)\end{array}$ \\
\hline $\begin{array}{l}\text { Farzaneh et } \\
\text { al. } 2017\end{array}$ & & + & & + & + & + & + & + & & + & & + & + & + & + & + & + & & + & + & + & & + & $\begin{array}{c}18 \\
(81,8 \%)\end{array}$ \\
\hline $\begin{array}{l}\text { Latifovic et } \\
\text { al. } 2015\end{array}$ & & + & + & + & + & + & + & + & + & & & + & - & - & - & + & + & + & + & + & + & + & + & $\begin{array}{c}18 \\
(81,8 \%)\end{array}$ \\
\hline $\begin{array}{l}\text { Allen et al. } \\
2015\end{array}$ & & + & + & + & + & + & + & + & + & & & + & - & + & + & + & + & + & + & + & + & + & + & $\begin{array}{c}20 \\
(90,9 \%)\end{array}$ \\
\hline $\begin{array}{l}\text { Tomioka et } \\
\text { al. } 2014\end{array}$ & & + & + & + & + & + & + & + & + & & & & + & - & + & + & + & + & + & + & + & + & + & $\begin{array}{c}20 \\
(90,9 \%)\end{array}$ \\
\hline $\begin{array}{l}\text { Colin et al. } \\
2018\end{array}$ & & + & + & + & + & + & + & + & + & & & + & + & + & + & + & + & + & + & + & + & & + & $\begin{array}{c}20 \\
(90,9 \%)\end{array}$ \\
\hline $\begin{array}{l}\text { Callahan et } \\
\text { al. } 2019\end{array}$ & & + & + & + & + & + & & + & - & - & & - & + & + & + & + & + & + & + & + & + & & + & $\begin{array}{c}17 \\
(77,3 \%)\end{array}$ \\
\hline $\begin{array}{l}\text { Hadkhale et } \\
\text { al. } 2019\end{array}$ & & + & + & + & + & + & + & + & & & & + & + & + & + & + & + & + & + & + & + & & & $\begin{array}{c}18 \\
(81,8 \%)\end{array}$ \\
\hline $\begin{array}{l}\text { Strand et al. } \\
2018\end{array}$ & & + & + & + & + & + & + & + & + & + & & + & + & - & + & + & + & + & + & + & + & + & & $\begin{array}{c}20 \\
(90,9 \%)\end{array}$ \\
\hline
\end{tabular}

Anexo II. Calidad de la evidencia revisiones sistemáticas/metanálisis

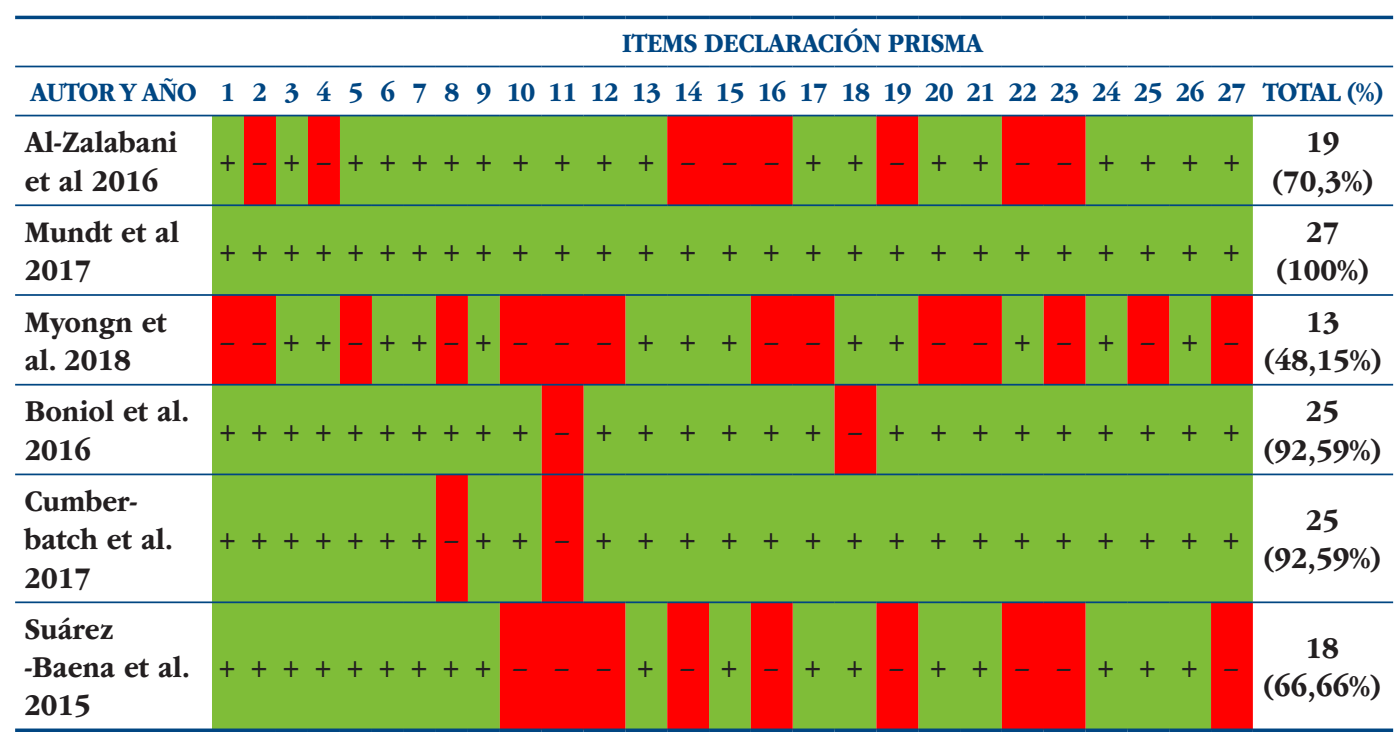


Anexo III. Estrategias de búsqueda

\begin{tabular}{|c|c|c|}
\hline Base de datos & $\begin{array}{l}\text { Descriptores y ecuación de búsqueda, combinaciones booleanas, términos } \\
\text { (MeSHTerms) }\end{array}$ & $\begin{array}{l}\text { Artículos } \\
\text { recuperados } \\
\text { (seleccionados) }\end{array}$ \\
\hline $\begin{array}{l}\text { Medline } \\
\text { (PubMed) }\end{array}$ & $\begin{array}{l}\text { (((urinary bladder neoplasm[MeSH Terms]) AND (occupational } \\
\text { exposure[MeSH Terms])) OR (("urinary bladder neoplasm"”[Title/Abstract] } \\
\text { OR "Bladder Tumor*"[Title/Abstract] OR "Urinary Bladder Cancer"[Title/ } \\
\text { Abstract] OR "Bladder Cancer"”[Title/Abstract]) AND ("occupational } \\
\text { exposure"[Title/Abstract] OR "laboral exposure"[Title/Abstract] OR } \\
\text { "industrial exposure"[Title/Abstract]))) NOT (genetic* OR polymorph* OR } \\
\text { gene) Filters: from 2015-2019 }\end{array}$ & $6(3)$ \\
\hline Embase & $\begin{array}{l}\text { \#1('bladder tumor'/exp OR 'bladder tumor') AND ('occupational exposure'/ } \\
\text { exp OR 'occupational exposure') } \\
\text { \#2('bladder tumor'/exp OR 'bladder tumor') AND ('occupational exposure'/ } \\
\text { exp OR 'occupational exposure') AND [embase]/lim } \\
\text { \#3\#2 AND (2015:py OR 2016:py OR 2017:py OR 2018:py OR 2019:py) } \\
\text { \#4 } 2 \text { AND 2015:py OR 2016:py OR 2017:py OR 2018:py OR 2019:py) AND } \\
\text { ([english]/lim OR [spanish]/lim) } \\
\text { \#5 genetic* OR polymorph* OR gene } \\
\text { \#6 \#4 NOT \#5 } \\
\text { \#7 \#4 NOT \#5 AND [embase]/lim }\end{array}$ & $12(3)$ \\
\hline SCOPUS & $\begin{array}{l}\text { ((TITLE-ABS-KEY(“urinary bladder neoplasm*”OR”Bladder } \\
\text { Tumor*”OR”Urinary Bladder Cancer"OR"Bladder Cancer*")AND TITLE- } \\
\text { ABS-KEY (“occupational exposure"OR"laboral exposure"OR"industrial } \\
\text { exposure")))AND NOT(TITLE-ABS-KEY(genetic*OR polymorph* OR } \\
\text { gene)) AND NOT INDEX (medline) AND LIMIT TO (DOCTYPE, "ar") } \\
\text { OR LIMIT-TO (DOCTYPE, "re"))AND(LIMIT-TO(subjarea, "MEDI")) AND } \\
\text { (LIMIT-TO (PUBYEAR, 2019) OR LIMIT-TO (PUBYEAR, 2018) OR LIMIT- } \\
\text { TO (PUBYEAR, 2017) OR LIMIT-TO (PUBYEAR, 2016) OR LIMIT-TO } \\
\text { (PUBYEAR, 2015) }\end{array}$ & $5(1)$ \\
\hline $\begin{array}{l}\text { WEB OF } \\
\text { SCIENCE }\end{array}$ & $\begin{array}{l}\text { \#1 "Urinary bladder neoplasm*" OR "Bladder tumor* OR "Urinary bladder } \\
\text { cancer*" OR "Bladder cancer" AND "Occupational exposure" } \\
\text { \#2 genetic OR polymorph* OR gene } \\
\text { \#1 NOT \# } 2\end{array}$ & $46(10)$ \\
\hline COCHRANE & $\begin{array}{l}\text { \#1 MeSH descriptor: (Urinary Bladder Neoplasms) } \\
\text { \#2 MeSH descriptor: (Occupational Exposure) } \\
\# 3 \# 1 \text { AND } \# 2\end{array}$ & $1(0)$ \\
\hline IBECS & $\begin{array}{l}\text { "Urinary bladder neoplasms" (palabras) AND "Occupational exposure" } \\
\text { (palabras) }\end{array}$ & $3(1)$ \\
\hline LILACS & $\begin{array}{l}\text { "Urinary bladder neoplasms" (palabras) AND "Occupational exposure" } \\
\text { (palabras) }\end{array}$ & 0 \\
\hline
\end{tabular}


Anexo IV. Tabla de evidencia de estudios incluidos en la revisión sistemática

\begin{tabular}{|c|c|c|c|c|}
\hline $\begin{array}{c}\text { AUTOR/ } \\
\text { AÑO }\end{array}$ & $\begin{array}{l}\text { País } \\
\text { Periodo }\end{array}$ & Diseño & $\begin{array}{l}\text { Población } \\
\text { (N) }\end{array}$ & RESULTADOS \\
\hline $\begin{array}{l}\text { Al-Zalabani et } \\
\text { al. 2016(17) }\end{array}$ & $1995-2015$ & RS / MA & $\begin{array}{l}\text { Población } \\
\text { general con } \\
\text { cáncer de vejiga } \\
\mathrm{N}=82 \text { estudios }\end{array}$ & $\begin{array}{l}\text { Los factores ocupacionales se consideran el segundo factor de } \\
\text { riesgo más importante para el cáncer de vejiga después del tabaco. } \\
\text { Trabajadores expuestos a aminas aromáticas, hidrocarburos } \\
\text { aromáticos policíclicos, tabaco y humo de tabaco, productos de } \\
\text { combustión y metales pesados presentan mayor riesgo }\end{array}$ \\
\hline $\begin{array}{l}\text { Mundt et al. } \\
2017(18)\end{array}$ & $1950-2016$ & $\mathrm{RS} / \mathrm{MA}$ & $\begin{array}{l}\text { Trabajadores } \\
\text { expuestos a } \\
\text { bitumen } \\
\mathrm{N}=82 \text { estudios }\end{array}$ & $\begin{array}{l}\text { No se evidenció aumento del riesgo de cáncer de vejiga asociado } \\
\text { a la exposición a bitumen. Meta-RR=1,09, CI } 95 \%=0,93-1,27 \text {. } \\
\text { Heterogeneidad moderada al incluir todos los estudios ( } \mathrm{I} 2=47,5 \% \text {, } \\
\mathrm{p}=0,006 \text { ); al excluir los estudios de menor calidad se obtuvo } \\
\text { menos heterogeneidad (I2=28,9\%, } \mathrm{p}=0,188 \text { ). } \\
\text { No se consideró la información sobre hábito tabáquico y otras } \\
\text { exposiciones ocupacionales. }\end{array}$ \\
\hline
\end{tabular}

\begin{tabular}{lllll}
\hline $\begin{array}{l}\text { Myong et al. } \\
\text { 2018(19) }\end{array}$ & 1989-2010 & RS / MA & $\begin{array}{l}\text { Pintores } \\
\text { N=31 estudios }\end{array}$ & $\begin{array}{l}\text { Los resultados de la evidencia científica cuentan con una serie de } \\
\text { metaanálisis que incluyen 11 cohortes y 28 caso-control muestran } \\
\text { un meta-RR para el cáncer de vejiga de 1.24 (IC 95\%: 1.16-1.33). }\end{array}$ \\
\hline
\end{tabular}

2015(13) estudios dirigidos profesiones expuestas a Aminas e Hidrocarburos aromáticos a relacionar policíclicos, estando los resultados limitados por las carencias efectos de propias del diseño de cada trabajo revisado. Las profesiones más exposición expuestas a riesgo de cáncer vesical son las relacionadas con laboral con la industria de hierro, acero y colorantes, minería de carbón, cáncer vesical trabajadores del caucho, pintores, agricultores, peluqueros, según los conductores de camiones y profesionales en contacto con criterios de sustancias explosivas, con predominio del sexo masculino en las inclusión poblaciones estudiadas (posiblemente porque la mayoría de los establecidos puestos en el sector industrial están ocupados por hombres). (nacionales e Entre las sustancias más relacionadas con el cáncer de vejiga internacionales). ocupacional se describen las Aminas aromáticas (Anilina, $\mathrm{N}=18$ estudios O-Toluidina, Bencidina, 4-aminobifenilo, Magenta) y los Hidrocarburos aromáticos policíclicos (Dinitrotolueno) y se infiere que mayor tiempo de exposición se relaciona con mayor riesgo de cáncer vesical.

\begin{tabular}{|c|c|c|c|c|}
\hline $\begin{array}{l}\text { Boniol et al. } \\
2016(20)\end{array}$ & $1967-2016$ & MA & $\begin{array}{l}\text { Trabajadores de } \\
\text { la industria del } \\
\text { caucho } \\
\mathrm{N}=105 \text { estudios }\end{array}$ & $\begin{array}{l}\text { Se encontró un riesgo aumentado de cáncer de vejiga en SRR } \\
\text { (IC 95\%) de } 1.36 \text { (1.18-1.57). Análisis estratificados mostraron } \\
\text { un riesgo más bajo para los trabajadores contratados más } \\
\text { recientemente, después de } 1960 \text { y 1970, con un SRR (IC 95\%) de } \\
1.06(0.66-1.71) \text { y } 0.81(0.40-1.64) \text { respectivamente. }\end{array}$ \\
\hline $\begin{array}{l}\text { Cumberbatch } \\
\text { et al. } 2017(8)\end{array}$ & $2015-2016$ & MA & $\begin{array}{l}\text { Trabajadores } \\
\text { de procesos } \\
\text { químicos, caucho, } \\
\text { tinte, camareros, } \\
\text { sanitarios, } \\
\text { electricistas, } \\
\text { fundición, } \\
\text { textil, bebidas, } \\
\text { bomberos, } \\
\text { artistas, mozos } \\
\text { de almacén y } \\
\text { conductores } \\
\mathrm{N}=25\end{array}$ & 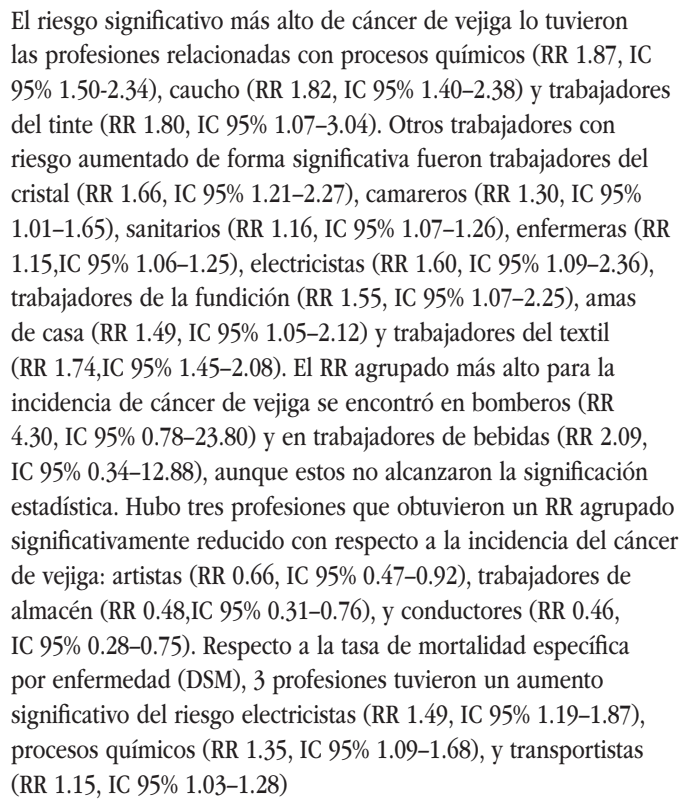 \\
\hline
\end{tabular}




\begin{tabular}{|c|c|c|c|c|}
\hline $\begin{array}{l}\text { AUTOR/ } \\
\text { AÑo }\end{array}$ & $\begin{array}{l}\text { País } \\
\text { Periodo }\end{array}$ & Diseño & $\begin{array}{l}\text { Población } \\
\text { (N) }\end{array}$ & RESULTADOS \\
\hline $\begin{array}{l}\text { Allen et al. } \\
2015(22)\end{array}$ & $\begin{array}{l}\text { EE. UU. } \\
1988- \\
2010\end{array}$ & Cohortes & $\begin{array}{l}\text { Trabajadores } \\
\text { de la industria } \\
\text { minera de } \\
\text { Minnesota. } \\
\mathrm{N}=40720\end{array}$ & $\begin{array}{l}\text { El SRI para cáncer de vejiga resultó aumentado, sin embargo, } \\
\text { ajustado por tabaquismo se atenuaba el efecto (SRI } 1.095 \% \text { 0.8-1- } \\
\text { 1, siendo el previo SRI 1.1 95\% 1.0-1.2). }\end{array}$ \\
\hline $\begin{array}{l}\text { Tomioka et } \\
\text { al. 2014(23) }\end{array}$ & $\begin{array}{l}\text { Japón } \\
\text { 1953-2011 }\end{array}$ & Cohortes & $\begin{array}{l}\text { Trabajado-res } \\
\text { expuestos a } \\
\text { bencidina y/o } \\
\text { beta- naftilamina. } \\
\mathrm{N}=224\end{array}$ & $\begin{array}{l}\text { Se identificó un aumento de SIR para el cáncer de vejiga ( } 7 \\
\text { casos, SIR 4.70, } 95 \% \text { CI 1.89-9.67) y un aumento de riesgo en } \\
\text { los sujetos expuestos para ambas poblaciones de referencia } \\
\text { (general o regional). El cáncer de vejiga mostró un aumento de } \\
\text { riesgo significativo en los grupos de corta (5.58, } 95 \% \text { 1.10-16.30) } \\
\text { y larga ( } 4.20,95 \% \text { IC 1.14-10.76) exposición. Los trabajadores } \\
\text { que empezaron a trabajar con BZ/BNA antes de } 1963 \text { tuvieron } \\
\text { un aumento de riesgo (4.36, 1.19-11.17) y en aquellos que } \\
\text { comenzaron con la exposición después de } 1964 \text { solo el cáncer } \\
\text { de vejiga mostró un aumento significativo del SIR (5.23, 95\% CI } \\
\text { 1.08-15.29). Al ajustar por tabaco, exposición adicional a Bis- } \\
\text { clorometil éter y edad de la primera exposición, la incidencia no } \\
\text { se vio afectada por la DOE (posiblemente por la pequeña n de } \\
\text { casos), no observándose un aumento significativo para el grupo de } \\
\text { exposición de larga duración (1.69 95\% CI 0.37-7.67). Se observó } \\
\text { un aumento de riesgo significativo independiente de la DOE, edad } \\
\text { o tiempo de la primera exposición, sin encontrarse asociación con } \\
\text { el tabaco (posible sesgo de clasificación no diferencial entre los } \\
\text { miembros vivos y fallecidos de la cohorte). }\end{array}$ \\
\hline
\end{tabular}

\begin{tabular}{llll}
\hline MacLeod et & Canadá. & Cohortes & Soldadores \\
al.(26) & 1991-2010 & retrospectivo & Nexp $=12.845$ \\
& & & Nno exp $=87.460$
\end{tabular}

Se comparó el grupo de soldadores con el grupo de referencia de no soldadores. Aparecieron 100 casos de cáncer de vejiga, con un HR (IC 95\%) de 1.40 (1.15-1.70. Se comparó también el grupo de soldadores con el grupo de referencia de no soldadores en trabajos 'blue-collar' únicamente obteniendo un HR (IC 95\%) de $1.47(1.21-1.79)$.

\begin{tabular}{llll}
\hline Koutros et al. & EEUU & $\begin{array}{l}\text { Cohortes } \\
\text { prospectivo }\end{array}$ & $\begin{array}{l}\text { Trabajado-res } \\
\text { aplicadores de } \\
\text { pesticidas. }\end{array}$
\end{tabular}
Aumento de riesgo de cáncer de vejiga en usuarios de bentazon $\mathrm{N}=54.344$ (RR:1,55, IC95\%=1,10-2,19), bromoxinil (RR:1,51, IC95\%=1,042,20), cloramben (RR: 1,56, IC95\%=1,10-2,22), diclofop-metil(RR: 1,85, IC95\%=1,01-3,42) e imazaquin RR:1,54, IC95\%=1,05-2,26) Al estratificar por hábito tabáquico: imazetapir (RR en el cuartil 4 vs no expuestos=3.03, IC95\%: 1,46-6,29, P-trend=0,004) entre los no fumadores

\begin{tabular}{|c|c|c|c|c|}
\hline $\begin{array}{l}\text { Callahan et al } \\
2019(16)\end{array}$ & $\begin{array}{l}\text { EEUU } \\
\text { 1993-2014 }\end{array}$ & Cohortes & $\begin{array}{l}\text { Trabajado-res } \\
\text { de lavanderías y } \\
\text { tintorerías } \\
\mathrm{N}=5.369\end{array}$ & $\begin{array}{l}\text { En el análisis de la exposición al tetracloroetileno, se observa una } \\
\text { relación de exposición-respuesta para el cáncer de vejiga }(\mathrm{HR} \\
\text { para exposición media }=4.2 ; \text { IC del } 95 \%=0.7,24.5 \text { y HR para } \\
\text { exposición alta }=9.2 ; \text { IC } 95 \%=1.1,76.7 \text { vs. no exposición; Ptrend } \\
=0.08 \text { ), con aumento del riesgo del mismo. La falta de información } \\
\text { sobre los hábitos de fumar de los sujetos es una limitación del } \\
\text { estudio. }\end{array}$ \\
\hline $\begin{array}{l}\text { Colin et al } \\
2018(27)\end{array}$ & $\begin{array}{l}\text { Francia } \\
\text { 2006-2012 }\end{array}$ & Caso-control & $\begin{array}{l}\text { Trabajado- } \\
\text { res varones } \\
\text { de fábricas } \\
\text { productoras de } \\
\text { acero. } \\
\text { Casos }=84 \\
\text { Controles }=251\end{array}$ & $\begin{array}{l}\text { Los resultados de este estudio sugieren que la exposición a fluidos } \\
\text { metalúrgicos puros se asocia con un mayor riesgo de cáncer de } \\
\text { vejiga entre } 5 \text { y } 25 \text { años después de la exposición. Se observó un } \\
\text { aumento muy marcado de la OR en relación con la duración de } \\
\text { la exposición a los estos fluidos metalúrgicos puros ((OR=1.13 } \\
\text { (1.02-1.25)) y con la duración de la exposición ponderada en } \\
\text { frecuencia a los mismos (OR=1.44 (0.97-2.14)). Estos resultados } \\
\text { son válidos tras ajustar por la duración del tabaquismo, número } \\
\text { medio de cigarrillos fumados por día, tiempo desde la interrupción } \\
\text { del hábito tabáquico y exposición a hidrocarburos policíclicos } \\
\text { aromáticos (HAP). La OR también aumentó con la exposición a los } \\
\text { fluidos metalúrgicos solubles y sintéticos, pero sin significación } \\
\text { estadística, así como a exposiciones a fluidos metalúrgicos con } \\
\text { anterioridad. }\end{array}$ \\
\hline
\end{tabular}




\begin{tabular}{|c|c|c|c|c|}
\hline $\begin{array}{l}\text { AUTOR/ } \\
\text { AÑo }\end{array}$ & $\begin{array}{l}\text { País } \\
\text { Periodo }\end{array}$ & Diseño & $\begin{array}{l}\text { Población } \\
\text { (N) }\end{array}$ & RESULTADOS \\
\hline $\begin{array}{l}\text { Farzaneh et } \\
\text { al. } 2017(1)\end{array}$ & $\begin{array}{l}\text { Irán 2009- } \\
2013\end{array}$ & Caso-control & $\begin{array}{l}\text { Habitantes de la } \\
\text { provincia de Yazd } \\
\text { con cáncer de } \\
\text { vejiga y sanos } \\
\text { Casos }=200 \\
\text { Controles }=200\end{array}$ & $\begin{array}{l}\text { La frecuencia de cáncer de vejiga fue significativamente superior } \\
\text { en los trabajos de alto riesgo, OR (IC 95\%) } 3.24 \text { (1.99-5.29). Se } \\
\text { observó el mayor incremento del riesgo de cáncer de vejiga en } \\
\text { trabajadores del metal comparados con el grupo control, contando } \\
\text { con } 12 \text { eventos entre los casos y } 3 \text { entre los controles, con una OR } \\
\text { (IC 95\%) } 6.45 \text { (1.76-23.68) }\end{array}$ \\
\hline $\begin{array}{l}\text { Hadkhale et } \\
\text { al 2016(24) }\end{array}$ & $\begin{array}{l}\text { Finlandia } \\
1961-2005\end{array}$ & Caso-control & $\begin{array}{l}\text { Trabajador- } \\
\text { es expuestos } \\
\text { a distintos } \\
\text { disolventes. } \\
\text { Casos }=113.343 \\
\text { Controles }= \\
566.715\end{array}$ & $\begin{array}{l}\text { Incremento del riesgo (HR }>1.10) \text { para tricloroetileno, tolueno } \\
\text { y benceno a alto nivel de exposición. Tricloroetileno HR: } 1.23 \text {, } \\
\text { IC95\%=1.12-1.40; tolueno HR:1,2, IC95\%=1,00-1,38; benceno } \\
\text { HR:1,16, IC95\%=1,04-1,312 }\end{array}$ \\
\hline $\begin{array}{l}\text { Latifovic et al. } \\
2015(21)\end{array}$ & $\begin{array}{l}\text { Canadá } \\
1994- \\
1997\end{array}$ & Caso-control & $\begin{array}{l}\text { Trabajador-es } \\
\text { expuestos a } \\
\text { emisiones de } \\
\text { motores diésel } \\
\text { y gasolina. } 1360 \\
\text { controles y } 658 \\
\text { casos }\end{array}$ & $\begin{array}{l}\text { Los expuestos alguna vez a altas concentraciones de diésel } \\
\text { tenían un riesgo de cáncer de vejiga aumentado respecto a los } \\
\text { no expuestos (OR 1.64, } 0.87-3.08 \text { ) siendo este resultado no } \\
\text { significativo, y aquellos con }>10 \text { años de exposición a diésel a } \\
\text { altas concentraciones tuvieron el doble de aumento de riesgo (OR } \\
2.45,1.04-5.74) \text {. Se observó un aumento de cáncer de vejiga en el } \\
\text { análisis de subgrupos de casos solo expuestos a gasolina y nunca } \\
\text { expuestos a diésel en más de un } 30 \% \text { del tiempo de exposición } \\
\text { (OR 1.59, 1.04-2.43) respecto a los no expuestos. }\end{array}$ \\
\hline $\begin{array}{l}\text { Strand et al } \\
2018(28)\end{array}$ & $\begin{array}{l}\text { Noruega } \\
1960-2015\end{array}$ & $\begin{array}{l}\text { Serie de } \\
\text { casos }\end{array}$ & $\begin{array}{l}\text { Trabajador- } \\
\text { es varones y } \\
\text { mujeres de la } \\
\text { Marina Real } \\
\text { Noruega } \\
\mathrm{N}=8.358\end{array}$ & $\begin{array}{l}\text { Entre el subgrupo de trabajadoras formado por limpiadoras } \\
\text { femeninas, hubo un aumento estadísticamente significativo } \\
\text { de cáncer de vejiga, mostrando un SIR (índice de incidencia } \\
\text { estandarizado) de } 2.33 \text {. La mortalidad por todas las causas fue } \\
\text { menor de lo esperado para los hombres, con un SMR (índice } \\
\text { de mortalidad estandarizado) de } 0.92 \text { (IC } 95 \% 0.88-0.96 \text { ) y más } \\
\text { parecida a la tasa de referencia para las mujeres, con un SMR de } \\
0.95 \text { (IC } 95 \% 0.88-1.01 \text { ). }\end{array}$ \\
\hline $\begin{array}{l}\text { Hadkhale } \\
\text { et al } \\
\text { 2019(29) }\end{array}$ & $\begin{array}{l}\text { Finlandia, } \\
\text { Noruega, } \\
\text { Suecia, } \\
\text { Dinamarca } \\
\text { e Islandia } \\
\text { 1961-2005 }\end{array}$ & $\begin{array}{l}\text { Serie de } \\
\text { casos }\end{array}$ & $\begin{array}{l}\text { Trabajador-es } \\
\text { de distintas } \\
\text { profesiones con } \\
\text { cáncer de vejiga } \\
\mathrm{N}=111.458\end{array}$ & $\begin{array}{l}\text { El SIR (tasa de incidencia) ajustado al tabaquismo para la mayoría } \\
\text { de las profesiones estaba más próximo a } 1.00 \text { que el SIR no } \\
\text { ajustado. Los SIR ajustados al tabaquismo más altos se observaron } \\
\text { en deshollinadores (SIR } 1.29 \text {, IC } 95 \% 1.05-1.56 \text { ), camareros (1.22, } \\
1.07-1.38 \text { ), peluqueros (1.14, 1.02-1.26), cocineros y mayordomos } \\
(1.12,1.01-1.25) \text {, impresores }(1.11,1.04-1.18) \text { y marineros (1.09, } \\
1.03-1.14) \text {. }\end{array}$ \\
\hline
\end{tabular}

